\title{
Segmentação Logística: um Estudo na Relação entre Fornecedores e Varejistas no Brasil
}

\author{
Kleber Figueiredo \\ Ilana Kogan Goldsmid \\ Rebecca Arkader \\ Maria Fernanda Hijjar
}

\begin{abstract}
RESUMO
Atualmente, na relação entre indústria e varejo no Brasil, há pressão para que os fornecedores melhorem o serviço ao cliente e reduzam seus custos logísticos. A segmentação logística pode apoiálos em seus esforços de posicionamento, uma das competências-chave em logística. A segmentação logística por benefícios ajuda os fornecedores a diferenciarem sua oferta, focando os atributos de serviço desejados pelos clientes e reduzindo custos, ao eliminar elementos que estes não valorizam. Este estudo teve por objetivo identificar segmentos de varejistas segundo suas expectativas em relação ao nível de serviço logístico prestado por seus fornecedores e caracterizar os segmentos assim obtidos através de variáveis de fácil acesso, tais como variáveis demográficas e organizacionais. Com base em dados de ampla pesquisa de survey, conduzida junto a varejistas brasileiros, foram identificadas soluções de dois e três segmentos de clientes com base em suas expectativas quanto ao serviço logístico prestado pelos fornecedores. No entanto, não se encontrou suporte suficiente para caracterizá-los segundo variáveis de fácil acesso, o que dificulta na prática sua identificação pelos fornecedores e a adequação de sua oferta de serviços logísticos às necessidades de cada segmento de clientes, bem como uma melhor gestão de seus custos logísticos.
\end{abstract}

Palavras-chave: segmentação logística; serviço ao cliente; relação varejo - indústria; segmentação por benefícios.

\begin{abstract}
In the present state of retailer-manufacturer relationships in Brazil, suppliers are being pressured to achieve improvements in customer service as well as reduction in logistics costs. In this context, logistics segmentation, one of the key logistics competences, is a valuable tool to support supplier positioning efforts. Benefit-based logistics segmentation helps suppliers to differentiate their offer, by focusing on attributes desired by customers, and to reduce costs, by eliminating elements that are not valued by them. The objective of this study was to identify retailer segments according to expectations concerning the level of logistics service they receive, as well as to characterize them by means of easy-access variables, such as demographic and organizational variables. Using data collected in a comprehensive survey research conducted with Brazilian retailers, both two and three segment solutions were identified based on customer expectations regarding logistics service provided by manufacturers. However, there was insufficient support for the characterization of these segments according to easy-access variables, making it difficult for manufacturers to identify them in practice and to match their offer of logistics services to the needs of each customer segment as well as to achieve better logistics cost management.
\end{abstract}

Key words: logistics segmentation; customer sevice; retailer-manufacturer buyer-supplier relationships; benefit-based segmentation. 


\section{INTRODUÇÃO}

A crescente aceitação da importância da logística e do gerenciamento de seus processos tem suscitado a condução de diversas pesquisas que buscam entender os fatores associados à qualidade das práticas logísticas. A questão principal passa a ser a identificação de elementos que estariam presentes naquelas empresas que, após terem adotado formalmente conceitos de logística, institucionalizandoos em suas estruturas e práticas organizacionais, passaram a apresentar desempenhos superiores aos de seus concorrentes.

Um conjunto de trabalhos, que merece citação pela continuidade das pesquisas, é o que tem sido conduzido por The Global Logistics Research Team da Michigan State University. Já em 1986, a primeira pesquisa teve como foco o estudo do que constituía a melhor prática na então emergente disciplina de logística. Os pesquisadores conseguiram evidências para validar as hipóteses de que a melhor prática logística era extremamente similar entre diferentes empresas, independentemente do setor de atividade, posição no canal de distribuição e tamanho. Um dos resultados desta pesquisa foi a proposta do modelo The Leading Edge Best Practice (Council of Logistics Management - CLM, 1995).

Outra pesquisa do mesmo grupo, iniciada em 1993, buscou entender, entre outras coisas, aspectos fundamentais do desempenho logístico superior, ou seja, como algumas empresas colocam em funcionamento práticas capazes de atender a clientes exigentes de forma melhor que seus concorrentes, tornam-se líderes em excelência operacional e ainda traduzem seu desempenho em vantagem competitiva e valor superior para os acionistas. Os resultados conduziram ao desenvolvimento do modelo World Class Logistics. O modelo, ilustrado na Figura 1 , destaca as competências logísticas perseguidas pelas empresas com desempenho logístico de classe mundial: posicionamento, integração, agilidade e mensuração. Os proponentes do modelo afirmam que o desempenho logístico de classe mundial seria resultado de alto nível de desempenho ou da busca de melhorias no desempenho nas quatro competências (CLM, 1995; Bowersox, Closs, Goldsby, \& Stank, 1998). 


\section{Figura 1: World Class Logistics Model}

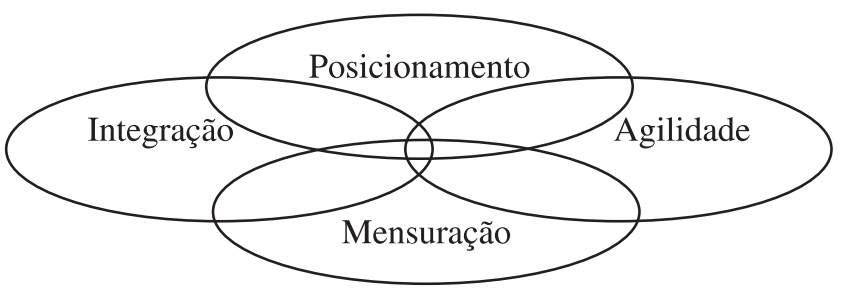

Fonte: CLM (1995).

A primeira competência - e a que é relevante para os objetivos do presente trabalho - é o posicionamento, ou seja, a forma como a empresa compete, o grupo de clientes-alvo, o tipo de serviço ofertado e sua comparação com a oferta dos concorrentes. O posicionamento se relaciona à estratégia e à estrutura. Enquanto a estratégia estabelece os objetivos e os meios para atingi-los, a estrutura é a forma como os recursos humanos e materiais se organizam para dar suporte à implementação da estratégia (CLM, 1995). Procurar um melhor desempenho nessa competência significa, primeiramente, definir com muita clareza a que clientes a empresa quer atender e o que esta vai oferecer a cada grupo assim determinado, já que a importância para diferentes clientes de distintos benefícios obtidos através de elementos de serviço ao cliente na logística não é a mesma (Christopher, 1992; Collins, Henchion, \& O’Reilly, 2001; Heskett, 1994; Stock \& Lambert, 1992). Estas duas definições caracterizam a segmentação logística (Lambert, 1992). A segmentação logística leva a empresa a conhecer melhor seus clientes em termos do que esperam quanto ao serviço logístico, proporcionando melhor emprego de recursos de modo a ofertar, de forma eficiente, os atributos de serviço que efetivamente criam valor para os clientes (Sharma \& Lambert, 1994).

Assim, ao mesmo tempo que as empresas fornecedoras começam a adotar um foco no serviço ao cliente para elevar o valor de sua oferta aos olhos do cliente (Christopher, 1992; Veeken \& Rutten, 1998), as empresas varejistas cada vez mais identificam o serviço ao cliente prestado por seus fornecedores como elemento fundamental para buscar sua própria competitividade (Ellram, La Londe, \& Weber, 1999), especialmente na medida em que isto contribui para melhorar sua eficiência operacional (Heskett, 1994).

O setor de super e hipermercados no Brasil vem passando por processo de consolidação, representado por movimentos de fusões, incorporações, associações e aquisições locais e globais (Saab \& Gimenez, 2000), com ampla participação de capital externo. Enquanto os movimentos de consolidação visam à redução de custos, aumento de eficiência e maior poder de negociação junto aos fornecedores, a internacionalização vem provocando a concorrência por preços e melhoria na 
qualidade dos serviços oferecidos pelo setor. Estes movimentos implicam a necessidade de a indústria brasileira melhorar o serviço a seus clientes e, ao mesmo tempo, reduzir seus custos logísticos. A segmentação logística constitui ferramenta adequada para lidar com estas exigências, na medida em que pode apoiar os fabricantes a entenderem o que seus clientes querem, podendo assim reduzir custos operacionais, ao evitar desperdícios ocasionados pela oferta de atributos que não são valorizados.

O objetivo deste trabalho é investigar a identificação de segmentos de clientes varejistas da indústria brasileira quanto às expectativas de nível de serviço logístico prestado por seus fornecedores, com base em ampla pesquisa conduzida junto a 486 encarregados de compras de super e hipermercados localizados em cinco capitais brasileiras. Além disso, busca-se também caracterizar os segmentos obtidos por meio de variáveis de fácil acesso, tais como variáveis demográficas e organizacionais.

Após esta introdução é apresentado o referencial teórico que serviu de base para a pesquisa. A seguir é descrita a metodologia utilizada na coleta e análise dos dados. A seguir são apresentados e discutidos os resultados, concluindo-se o trabalho com uma apreciação de sua contribuição teórica e prática.

\section{Referencial Té́rico}

O resultado do esforço de todo o sistema logístico é o serviço ao cliente (Lambert, Stock, \& Ellram, 1998). Este último deve ser visto como a criação das utilidades de tempo e lugar, o que equivale a considerar que produtos não têm valor, se não estiverem disponíveis para o cliente na hora e lugar desejados (Bowersox \& Closs, 1996; Christopher, 1992; Lambert et al., 1998). Além disso, há a utildade de forma, dado que os produtos também devem estar livres de avarias (Emerson \& Grimm, 1996).

Sem contradizer as definições anteriores, mas com uma visão um pouco mais holística, La Londe, Cooper e Noordewier (1988) conceituam o serviço ao cliente como processo de fornecimento de benefícios de valor agregado para a cadeia de suprimentos com eficiência em custos. Isto equivale a dizer que a oferta de bom serviço deve ter impacto na eficiência operacional do cliente, diminuindo o trabalho interno ou mesmo "artifícios" para controle da incerteza, tais como estoques de segurança. De fato, um mau serviço pode acarretar custos indesejáveis aos clientes, tais como perda de vendas - ocasionadas por falta de produtos - ou altos custos de manutenção de estoques de segurança - devido à inconsistência no prazo de entrega do fornecedor. 
Uma vez que os benefícios proporcionados pelo serviço ao cliente são de distintas naturezas, podem ser mais bem expressos através de dimensões e/ou atributos. Um exemplo é a classificação proposta por Bowersox e Closs (1996). Para estes autores, o serviço ao cliente poderia ser dividido em serviço básico e serviço de valor agregado. Os serviços básicos seriam compostos de três dimensões: disponibilidade, desempenho operacional e confiabilidade. Já os serviços de valor agregado, bem diferentes dos serviços básicos, seriam desenvolvidos para clientes específicos, adequando-se a cada caso. Cada uma das dimensões corresponde a um conjunto de atributos. Assim, por exemplo, a disponibilidade seria representada pela freqüência de stockout, número de pedidos entregues completos e pelo percentual entregue do pedido total. O desempenho operacional corresponderia, entre outros atributos, ao tempo de ciclo e sua consistência. Os serviços de valor agregado poderiam incluir a confecção de embalagens especiais, o sistema de reabastecimento contínuo e o estoque gerenciado pelo fornecedor, entre outros. Christopher (1992), por sua vez, desenvolveu a idéia de envoltório de serviço, em que o produto "da forma como ele sai da fábrica" constituiria um núcleo, cujo envoltório seria composto pelo valor adicionado proporcionado por atividades logísticas tais como serviço personalizado, cumprimento de prazos e maior freqüência de entregas, bem como por elementos tais como embalagem, propaganda e marca da empresa.

A literatura sobre serviço ao cliente é bastante rica no que se refere à diversidade de atributos, podendo ser mencionados, além dos já citados, os trabalhos de La Londe et al. (1988), Lambert e Harrington (1989), Mangold e Faulds (1993) e Ellram et al. (1999). Não é tarefa fácil alinhar as expectativas dos clientes com o que os fornecedores querem ou podem oferecer em termos de atributos de serviços, podendo-se encontrar uma solução na busca de grupos de clientes caracterizados por grande semelhança em suas necessidades, através da segmentação (Christopher, 1992). Uma maneira de se entender a segmentação logística reside em enquadrá-la como meio-termo entre a customização e uma abordagem genérica padronizada (Murphy \& Daley, 1994). $\mathrm{Na}$ abordagem genérica, o mesmo serviço seria provido para todos os clientes, independentemente de suas diferenças (uma logística "genérica"); já na abordagem personalizada, seria possível servir a cada cliente individualmente (uma logística "customizada").

Há diferenças entre as abordagens de marketing e de logística no que se refere ao serviço ao cliente e aos níveis de serviço: enquanto a abordagem de marketing vê o serviço ao cliente como um conjunto de atividades para garantir a lealdade de clientes, sendo principalmente de natureza perceptual, a perspectiva de logística considera atributos observáveis e mensuráveis, cujo nível desejado pode ser avaliado (Tucker, 1994). 
Sharma e Lambert (1994) sugerem que a segmentação de mercados institucionais seja dividida em dois grandes grupos, um de identificação/acesso e outro de necessidades/benefícios. A primeira seria a mais popular devido à facilidade de obtenção das informações - que de modo geral são públicas - e implementação. Já a orientação por necessidades/benefícios se basearia nas necessidades subjacentes e benefícios procurados pelo comprador, ou seja, o agrupamento se daria de acordo com as expectativas dos clientes com relação a determinado produto ou serviço. Esta abordagem sugere a implementação de estratégias de mercado diferenciadas para cada segmento de interesse do fornecedor. A segmentação por benefícios teria também a vantagem adicional de apresentar oportunidades consistentes para a criação de apelos diferentes para segmentos específicos (Christopher, 1992).

A utilização de expectativas de serviço como base para segmentação se propõe como uma alternativa interessante para as variáveis de grupamento tradicionalmente utilizadas, tais como as demográficas, tendo em vista que diferentes níveis de expectativas estariam relacionados a diferentes comportamentos de compra, reforçando a idéia de uma estratégia diferenciada para cada segmento (Díaz-Martin, Iglesias, Vasquez, \& Ruiz, 2000; Rao \& Wang, 1995).

A proposta de Sharma e Lambert (1994) seria o desenvolvimento de uma segmentação por necessidades/benefícios, mas acompanhada de uma identificação dos clientes de acordo com suas variáveis demográficas, de modo a facilitar o enquadramento de novos clientes nos grupos anteriormente formados. Para estes autores, uma segmentação por benefícios pura não tem valia, se não for operacionalmente viável.

Christopher (1983) sugeriu as seguintes etapas para uma segmentação por serviço ao cliente:

1. Identificação dos principais componentes de serviço na visão dos clientes.

2. Estabelecimento da importância relativa que os clientes atribuem aos componentes de serviço identificados.

3. Identificação dos grupos de clientes de acordo com a similaridade de suas preferências de serviço.

Mais tarde, Sharma e Lambert (1994) ressaltaram a importância de se associarem variáveis demográficas a cada segmento, sugerindo o modelo apresentado na Figura 2: 


\section{Figura 2: Modelo para Segmentação de Mercados Baseada no Serviço ao Cliente}

\begin{tabular}{|c|c|c|c|c|}
\hline $\begin{array}{l}\text { Identificação } \\
\text { dos atributos } \\
\text { de serviço ao } \\
\text { cliente }\end{array}$ & $\begin{array}{c}\text { Pesquisa } \\
\text { com clientes }\end{array}$ & $\begin{array}{l}\text { Análise de dados: } \\
\text { Determinação das } \\
\text { dimensões do } \\
\text { serviço ao cliente }\end{array}$ & $\begin{array}{l}\text { Análise de dados: } \\
\text { Grupamento dos } \\
\text { clientes com } \\
\text { necessidades } \\
\text { similares }\end{array}$ & $\begin{array}{l}\text { Análise de dados: } \\
\text { Identificação dos } \\
\text { segmentos com } \\
\text { características } \\
\text { comuns }\end{array}$ \\
\hline
\end{tabular}

Fonte: Sharma e Lambert, 1994, p. 52.

\section{Metodologia}

Para alcançar os objetivos deste trabalho foram testadas duas hipóteses formuladas a partir do modelo de Sharma e Lambert (1994):

H1: As empresas varejistas podem ser segmentadas de acordo com as expectativas que nutrem em relação ao nível de serviço proporcionado por seus fornecedores.

H2: Os segmentos por benefícios esperados podem ser caracterizados por meio de variáveis de fácil acesso/identificação.

O levantamento de dados para o teste de hipóteses foi realizado através de ampla pesquisa de benchmarking de serviço ao cliente realizada em cinco capitais brasileiras, com o objetivo de avaliar a qualidade do serviço de distribuição prestado pelos fornecedores de quatro classes de produtos aos seus clientes varejistas. A pesquisa foi realizada em 2002 e envolveu 486 responsáveis pelas compras de supermercados com quatro ou mais check outs. Cabe ressaltar que uma observação individual não se refere necessariamente a uma loja, mas pode estar representando toda uma cadeia, no caso de compras centralizadas. Assim, podese considerar que o número de lojas mensuradas foi maior do que o número de observações. A Tabela 1 mostra a distribuição da amostra em cada uma das cinco capitais pesquisadas.

Tabela 1: Distribuição da Amostra por Capitais

\begin{tabular}{|l|c|}
\hline \multicolumn{1}{|c|}{ Capital } & Respondentes (no) \\
\hline Belo Horizonte & 114 \\
\hline Curitiba & 63 \\
\hline Recife & 88 \\
\hline Rio de Janeiro & 99 \\
\hline São Paulo & 122 \\
\hline
\end{tabular}


Os dados foram coletados por meio da aplicação aos respondentes selecionados de questionário estruturado, cujas questões formuladas continham a operacionalização das variáveis utilizadas para testar as hipóteses da pesquisa. A aplicação dos questionários se deu por entrevistas pessoais, o que permitiu diminuir o número de erros e respostas incompletas, contribuindo para a qualidade dos resultados da pesquisa.

Para medir as expectativas dos varejistas em relação ao desempenho dos fornecedores foi considerado um conjunto de atributos de serviço ao cliente dentro de nove dimensões de serviço, tomando-se como base os estudos de La Londe et al. (1988), Christopher (1992), e Bowersox e Cooper (1992).

As variáveis de identificação/acesso se basearam no modelo de Shapiro e Bonoma (1984): tamanho da empresa, localização e abordagem de compras. Adicionalmente, foi utilizada também a classe de produto.

A Tabela 2, a seguir, reúne todas as características das variáveis utilizadas na pesquisa.

\section{Tabela 2: Caracterização das Variáveis Utilizadas na Pesquisa}

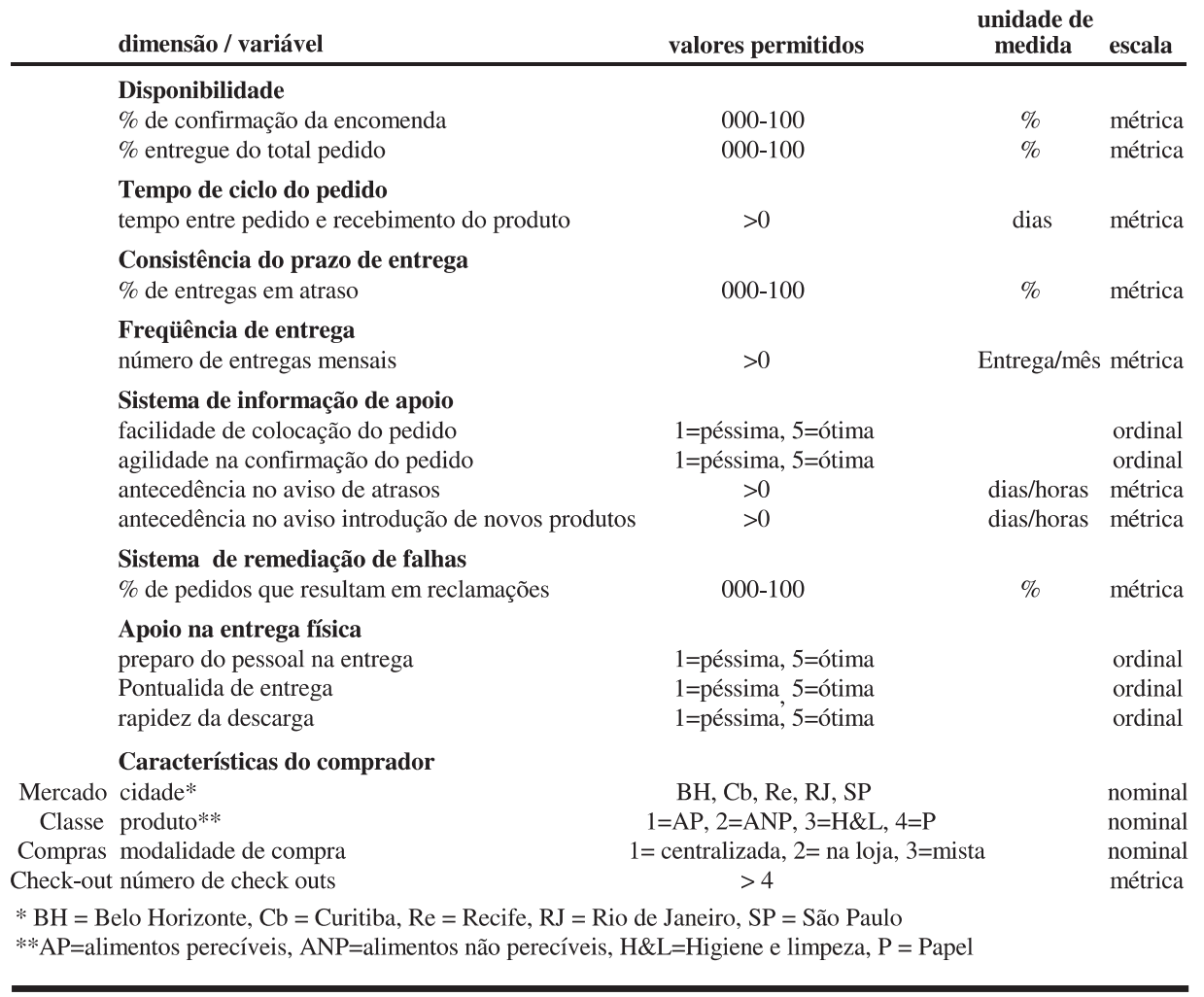


O tratamento dos dados seguiu um conjunto de procedimentos. No que diz respeito à hipótese 1, efetuaram-se: análise descritiva (histogramas e gráficos de barras), detecção e retirada de outliers (distância de Mahalanobis), detecção de multicolinearidade e retirada de variáveis, aplicação de algoritmos de análise de cluster (métodos hierárquico Ward's e não hierárquico), validação dos clusters (testes de significância estatística Mann-Whitney U e Kruskal-Wallis H e análise discriminante) e a descrição dos clusters em função das expectativas. Para a hipótese 2 foram descritos os clusters em função das variáveis de identificação/ acesso. Todas as manipulações estatísticas foram feitas com o auxílio do software SPSS.

No que se refere às limitações, elas são de duas naturezas. A primeira está relacionada com a possível subjetividade nas respostas a questões de natureza perceptual. A segunda limitação diz respeito ao uso da análise de cluster, tendo em vista tratar-se de procedimento principalmente exploratório e descritivo (Hair, Anderson, Tatham, \& Black, 1998). De fato, as soluções proporcionadas por uma análise de cluster não são únicas, dado que a classificação dos objetos depende do procedimento, podendo ser obtidas soluções diferentes com a variação de alguns elementos. Por outro lado, a análise de cluster também é bastante sensível às variáveis escolhidas, as quais têm impacto substancial na solução. Deste modo, a generalização dos resultados da pesquisa aqui relatada para outros setores, contextos e variáveis deve ser considerada com cautela.

\section{Apresentação e Discussão dos Resultados}

\section{Primeira Hipótese}

A primeira hipótese testou a possibilidade de se segmentarem os super e hipermercados, estudados de acordo com as expectativas de serviço ao cliente. Para tanto foram seguidos os procedimentos já mencionados. A apresentação dos resultados começa a partir da aplicação dos algoritmos que permitem identificar o número relevante de clusters. A Tabela 3 apresenta os coeficientes de aglomeração e sua variação. 


\section{Tabela 3: Coeficientes de Aglomeração para Definir o Número de Clusters}

\begin{tabular}{|ccc|}
$\mathbf{n}^{\mathbf{0}}$ de clusters & $\begin{array}{c}\text { Coeficiente de } \\
\text { aglomeração }\end{array}$ & $\begin{array}{c}\text { variação } \\
\text { do coef. }\end{array}$ \\
\hline 10 & 1785.714 & $5.7 \%$ \\
9 & 1887.917 & $6.1 \%$ \\
8 & 2003.387 & $8.1 \%$ \\
7 & 2165.098 & $8.1 \%$ \\
6 & 2339.444 & $8.5 \%$ \\
5 & 2538.346 & $8.2 \%$ \\
4 & 2746.471 & $8.2 \%$ \\
\hline $\mathbf{3}$ & $\mathbf{2 9 7 0 . 4 6 2}$ & $\mathbf{1 0 . 4 \%}$ \\
$\mathbf{2}$ & $\mathbf{3 2 7 9 . 0 3 7}$ & $\mathbf{1 5 . 4 \%}$ \\
\hline 1 & 3784.000 & \\
\hline
\end{tabular}

O percentual de mudança do coeficiente de aglomeração auxilia na identificação dos aumentos relativos na heterogeneidade do cluster. Os maiores aumentos de percentagem ocorrem de três para dois clusters e de dois para um. Assim, foram estudadas as soluções de três e dois clusters.

Em uma primeira verificação da validade dos clusters, foram aplicados os testes de significância Mann-Whitney U (para dois grupos) e Kruskal-Wallis (para três grupos). Enquanto a solução de 3 clusters apresentou diferença em todas as variáveis, a solução de dois clusters não permite a confirmação de diferença significativa entre os clusters para as variáveis: antecedência no aviso de atrasos e antecedência no aviso de novos produtos.

Ambas as soluções foram levadas para a análise não hierárquica, de modo a se obter a solução final dos conglomerados. A aplicação do método não hierárquico tem como objetivo aprimorar os resultados do procedimento hierárquico, dado que é menos sujeito à influência de outliers. Foram utilizados os centróides gerados no método hierárquico como raízes para o método não hierárquico. Após a aplicação do método não hierárquico, foi reduzido o número de variáveis que não apresentavam diferença estatística significativa para a solução de dois clusters. Apenas a variável "antecedência no aviso de atrasos" não passou no teste de significância a $5 \%$.

A comparação dos resultados dos dois métodos pode ser observada nas Tabelas 4 e 5 com as matrizes de estrutura da análise; os clusters gerados pelos dois métodos são bastante similares, o que colabora para validar a estabilidade das soluções. 


\section{Tabela 4: Matriz de Estrutura para a Solução de Dois Clusters}

\begin{tabular}{|l|c|}
\hline & Função \\
\cline { 2 - 2 } & 1 \\
\hline \% entregue do total pedido & .472 \\
$\%$ de entregas em atraso & -.438 \\
\% pedidos que resultam em reclamação & -.432 \\
pontualidade de entrega & .387 \\
tempo entre pedido e recebimento do & -.178 \\
produto & .076 \\
número de entregas mensais & .056 \\
antecedência no aviso novos produtos & -.027 \\
antecedência no aviso de atrasos & \\
\hline
\end{tabular}

Tabela 5: Matriz de Estrutura para a Solução de Três Clusters

\begin{tabular}{|l|r|r|}
\hline \multirow{2}{*}{} & \multicolumn{2}{|c|}{ Função } \\
\cline { 2 - 3 } & 1 & \multicolumn{1}{|c|}{2} \\
\hline \% entregue do total pedido & -.508 & .169 \\
\% pedidos que resultam em & .483 & -.133 \\
reclamação & .444 & .038 \\
\% de entregas em atraso & -.441 & .171 \\
pontualidade de entrega & .093 & .506 \\
antecedência no aviso de atrasos & .306 & .498 \\
tempo entre pedido e recebimento do & -.018 & .358 \\
produto & -.093 & -.161 \\
antecedência no aviso novos & & \\
nrodutos & & \\
\hline
\end{tabular}

A fim de melhor entender e descrever os clusters, primeiramente será apresentada a situação de dois clusters. Estes foram analisados tendo como padrão de comparação o estereótipo de um cliente exigente. Tal padrão e uma síntese dos grupos são apresentados na Tabela 6 a seguir: 


\section{Tabela 6: Comparação entre um Padrão e os Dois Clusters}

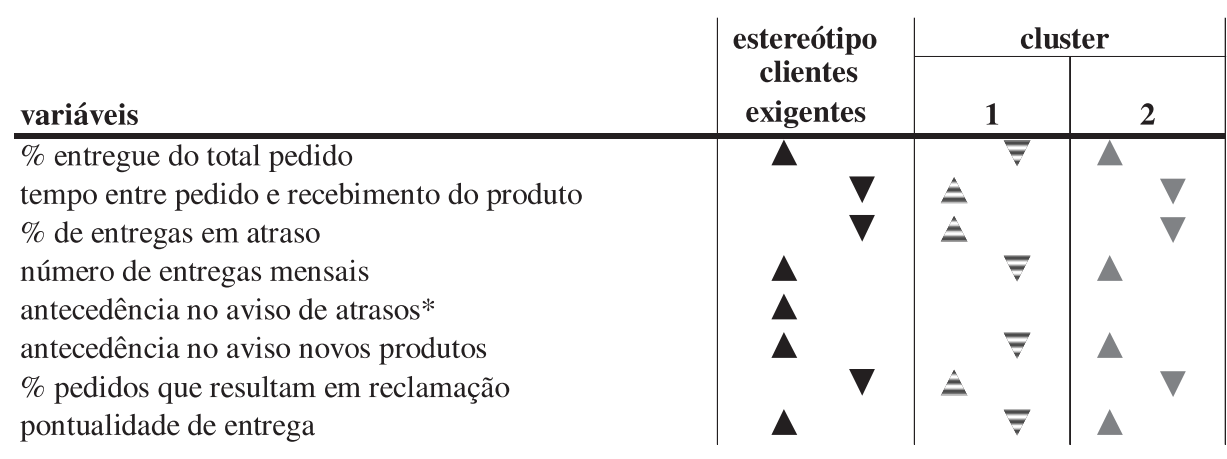

* esta variável não apresenta diferença significativa entre os grupos.

Legenda: Os símbolos $\boldsymbol{\Delta} \boldsymbol{\nabla}$ indicam se o estereótipo dos clientes exigentes aponta para maior ou para menor, respectivamente, em cada uma das variáveis. Assim, por exemplo, o cliente exigente quer um maior percentual do total pedido, mas exige um tempo menor entre o pedido e recebimento do produto. Quando no cluster identificado o símbolo está cheio, é porque há coincidência com o estereótipo; quando está entrecortado, é porque não há coincidência.

Assim, poder-se-ia considerar que o cluster 1, doravante chamado de complacente, não tem muitas exigências, aceitando maior tempo de ciclo, maior número de entregas atrasadas e mais pedidos que resultem em reclamação.

Em contrapartida, o segundo cluster, de agora em diante denominado exigente, espera de seus fornecedores maior nível de entregas completas (ou seja, disponibilidade), maior freqüência de entregas, maior antecedência no aviso de novos produtos e pontualidade.

Os coeficientes da matriz de estrutura na análise discriminante apontaram as variáveis que mais contribuem para a diferenciação dos grupos: percentual entregue do total pedido, percentual de entregas em atraso, percentual de pedidos que resultam em reclamação e pontualidade de entrega. Logo, variáveis associadas ao sistema de informação de apoio, como antecedência no aviso de novos produtos e antecedência no aviso de atrasos, a freqüência de entrega e o tempo de ciclo do pedido não são tão importantes na caracterização dos distintos grupos.

A Tabela 7 apresenta o tamanho dos grupos para a solução de dois clusters. Como pode ser observado, o grupo de exigentes supera em muito o número de complacentes, fato interessante que merece investigação. 


\section{Tabela 7: Tamanho dos Grupos na Amostra para Solução de Dois Clusters}

\begin{tabular}{lcc}
\multicolumn{3}{c}{ tamanho dos grupos } \\
\hline grupos & observações & $\%$ \\
\hline complacente & 161 & $34.0 \%$ \\
exigente & 313 & $66.0 \%$ \\
Total & 474 & $100 \%$
\end{tabular}

Pode-se concluir que uma divisão da amostra em dois grupos separa os varejistas em um segmento sem muitas exigências e outro, bem maior, mais preocupado em ser bem servido por seus fornecedores. Uma diferenciação de nível de serviço parece crítica, para que os fornecedores não desperdicem esforços com atributos que não acrescentam valor para os clientes.

Na solução com três clusters os grupos foram igualmente analisados, tendo como padrão de comparação o estereótipo do cliente exigente. Tal padrão e a síntese dos grupos são apresentados na Tabela 8 a seguir:

\section{Tabela 8: Comparação entre um Padrão e os Três Clusters}

\begin{tabular}{|c|c|c|c|c|}
\hline \multirow[b]{2}{*}{ variáveis } & \multirow{2}{*}{$\begin{array}{c}\text { estereótipo } \\
\text { clientes } \\
\text { exigentes }\end{array}$} & \multicolumn{3}{|c|}{ cluster } \\
\hline & & 1 & 2 & 3 \\
\hline $\begin{array}{l}\text { \% entregue do total pedido } \\
\text { tempo entre pedido e recebimento do produto } \\
\% \text { de entregas em atraso } \\
\text { número de entregas mensais } \\
\text { antecedência no aviso de atrasos } \\
\text { antecedência no aviso novos produtos } \\
\% \text { pedidos que resultam em reclamação } \\
\text { pontualidade de entrega }\end{array}$ & $\begin{array}{ll} & \nabla \\
\Delta & \nabla \\
\Delta & \\
\Delta & \nabla\end{array}$ & 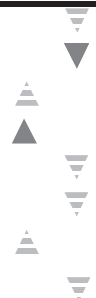 & 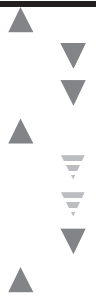 & 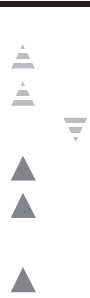 \\
\hline
\end{tabular}

Legenda: Os símbolos $\boldsymbol{\Delta} \boldsymbol{\nabla}$ indicam se o estereótipo dos clientes exigentes aponta para maior ou para menor, respectivamente, em cada uma das variáveis. Assim, por exemplo, o cliente exigente quer um maior percentual do total pedido, mas exige um tempo menor entre o pedido e recebimento do produto. Quando no cluster identificado o símbolo está cheio, é porque há coincidência com o estereótipo; quando está entrecortado, é porque não há coincidência.

Como na solução de dois clusters, aqui também o cluster 1 tem como característica mais forte a "complacência", sem grandes exigências, aceitando maior número de entregas atrasadas e mais pedidos que resultem em reclamação e, em contrapartida, menos pedidos entregues completos, pouca antecedência no aviso de problemas e pouca exigência com pontualidade de entrega. Os únicos atributos em que os complacentes se mostram exigentes são o tempo de ciclo e a frequiência de entregas. 
O segundo cluster, por sua vez, continua se destacando por sua exigência, esperando de seus fornecedores maior nível de serviço em todos os atributos, com exceção de antecedência no aviso de atrasos e de novos produtos.

Já o terceiro cluster é composto por elementos dos dois grupos da solução de dois clusters, com praticamente metade dos casos originados em cada grupo anterior. Este grupo tem como característica marcante o fato de não se destacar em termos de qualquer exigência quanto aos aspectos de serviço, com exceção do sistema de informação de apoio, fazendo as maiores exigências quanto à antecipação no aviso de atrasos e introdução de novos produtos. Assim, sentem necessidade de saber com antecedência a existência de mudanças, ou seja, de estarem bem informados.

Para a solução de três grupos, o cálculo do potency index aponta as mesmas variáveis listadas para a solução de dois segmentos como sendo as que mais contribuem para a diferenciação dos grupos. No entanto, surge também a variável antecedência no aviso de atrasos dentre o grupo das mais importantes, o que seria esperado, já que é uma das variáveis responsáveis pela formação do terceiro grupo.

Quanto ao tamanho dos grupos, assim como na solução de dois clusters, os exigentes aparecem em número muito maior - $61 \%$ da amostra, conforme Tabela 9 - sendo o grupo dos bem informados muito pequeno, quando comparado aos demais.

\section{Tabela 9: Tamanho dos Grupos na Amostra para Solução de Três Clusters}

\begin{tabular}{lcc}
\multicolumn{3}{c}{ tamanho dos grupos } \\
\hline grupos & observações & $\%$ \\
\hline complacente & 140 & $29.5 \%$ \\
exigente & 288 & $60.8 \%$ \\
bem informado & 46 & $10 \%$ \\
Total & 474 & $100 \%$
\end{tabular}

A análise do perfil dos clusters tanto para a solução de dois grupos quanto para a solução de três grupos, reforça a validação da hipótese de haver grupos de varejistas com expectativas distintas, a partir do momento em que é possível identificar a diferença de perfil dos segmentos.

Em suma, há indícios da existência de grupos de varejistas com expectativas distintas quanto ao nível de serviço proporcionado por seus fornecedores. 


\section{Segunda Hipótese}

Para verificar a hipótese de que segmentos por benefícios podem ser caracterizados por variáveis de fácil acesso/identificação, os grupos foram descritos de acordo com as variáveis de fácil acesso para ambas as soluções anteriores, com dois e três clusters. Como se mostra a seguir, não foram encontradas fortes diferenças quanto às variáveis localização, produto, tamanho e compras, a não ser para o pequeno grupo de varejistas bem informados na solução de três clusters, não se evidenciando sustentação para a segunda hipótese.

\section{Solução de Dois Clusters}

Os gráficos a seguir descrevem os grupos em relação às variáveis de fácil acesso. Os complacentes parecem contar com uma proporção considerável de varejistas da cidade do Rio de Janeiro, maior presença de compradores de alimentos perecíveis, mais compras mistas em detrimento de compras apenas nas lojas e uma presença um pouco maior do pequeno e médio varejo.
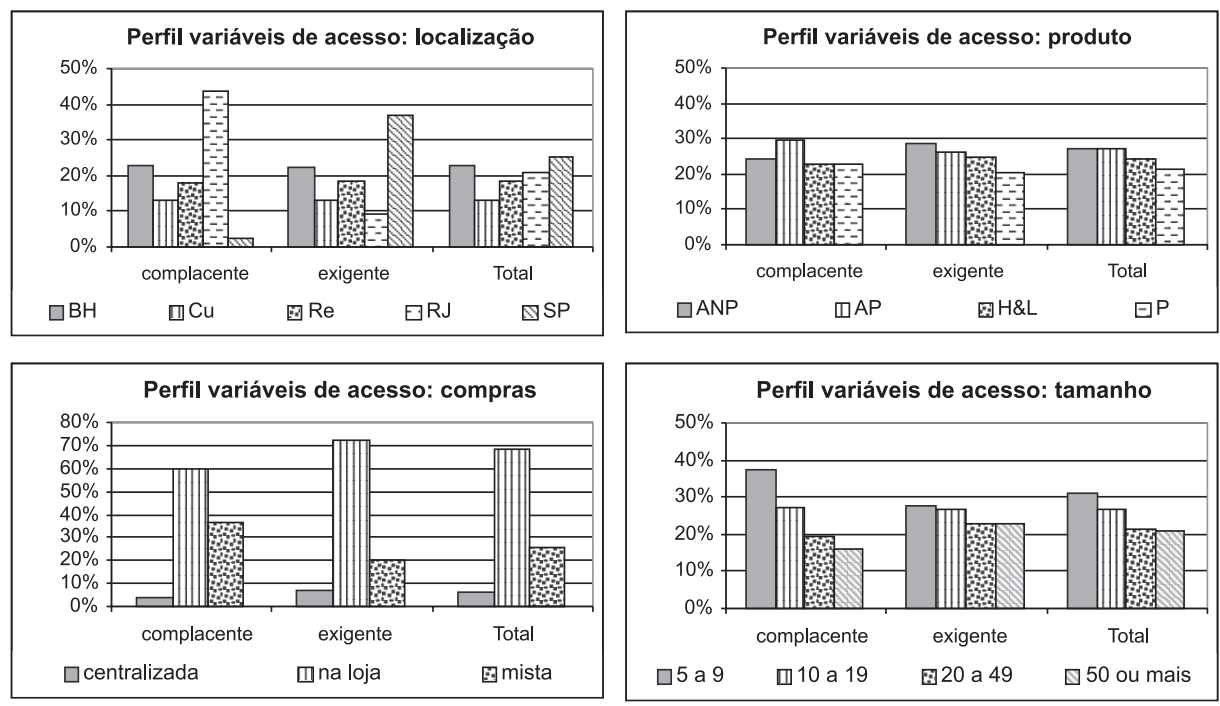

O fato de os complacentes terem forte presença de compradores de alimentos perecíveis é bastante curioso e aparentemente paradoxal. No entanto, a falta de exigência quanto ao nível de serviço logístico pode estar relacionada ao fato de que este grupo é representado, em sua maioria, pelo pequeno e médio varejo. Deste modo, o seu caráter pouco exigente talvez tenha a ver com seu reduzido poder de barganha em face da indústria, mais do que com qualquer relação ao tipo de produto comprado. 
No que se refere aos exigentes, este grupo chama a atenção pela concentração de varejos paulistas; no entanto, nenhuma das outras variáveis demográficas parece diferenciá-lo significativamente com relação ao total da amostra.

Em resumo, a solução de dois clusters apresenta diferença de expectativa, de acordo com a localização do varejo. No entanto, a diferença parece existir apenas entre os mercados de Rio e São Paulo. O fato de o Rio representar parte significativa dos complacentes causa estranheza, uma vez que se trata de mercado bem esclarecido e próximo das fontes produtoras.

\section{Solução de Três Clusters}

Os gráficos a seguir permitem visualizar os grupos em função das variáveis de fácil acesso/identificação.
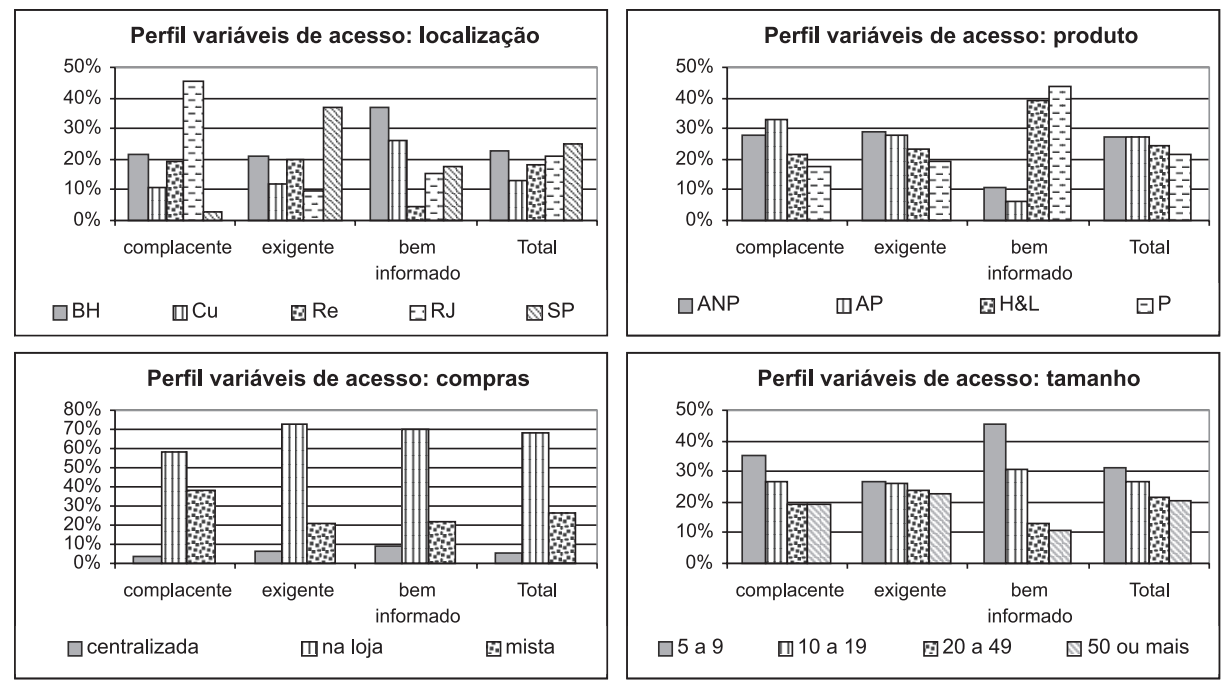

Assim como na solução de dois clusters, os complacentes parecem contar com proporção significativa de varejos na cidade do Rio de Janeiro, maior presença de compradores de alimentos perecíveis, mais compras mistas em detrimento de compras apenas nas lojas e uma presença ligeiramente superior de pequenos e médios varejistas.

O grupo dos exigentes chama a atenção pela concentração de varejos paulistas. No entanto, nenhuma das outras variáveis demográficas parece diferenciá-lo significativamente em relação ao total da amostra.

Finalmente, os bem informados constituem um pequeno grupo (apenas 46 observações, ou 9,7\% da amostra), formado por observações originadas, em 
parcelas praticamente iguais, nos grupos complacentes e exigentes da solução de dois clusters. O grupo se destaca pela presença maior de varejistas de Belo Horizonte e Curitiba, produtos de papel e de higiene e limpeza e presença do pequeno varejo. É o grupo mais fácil de ser caracterizado mediante o emprego das variáveis de fácil acesso. No entanto, pelo fato de ser um grupo pequeno, caberia ao fornecedor usuário da informação refletir sobre a viabilidade prática e financeira de considerá-lo separadamente.

\section{CONCLUSÕES}

Os resultados obtidos permitem concluir que as empresas varejistas podem ser segmentadas de acordo com as expectativas que nutrem em relação ao nível de serviço ofertado por seus fornecedores. De fato, a amostra pôde ser dividida em dois segmentos (exigentes e complacentes) ou três segmentos (exigentes, complacentes e um pequeno grupo de bem informados). Fica evidenciada, na amostra considerada, a preponderância do grupo de varejistas exigentes - em ambas soluções, estes representam mais de $60 \%$ das observações, levando à conclusão de que já há expressivo nível de conscientização das vantagens de um melhor serviço logístico por parte dos varejistas brasileiros.

Observando-se o perfil dos grupos, para ambas as soluções, conclui-se que o uso de uma estratégia única de serviço para todos os varejistas pode representar desperdício de recursos - caso seja adotado um alto nível de serviço - ou perda de clientes - se a opção for por um nível de serviço inferior. A melhor estratégia seria definir que grupo é mais vantajoso servir, tendo em vista seu tamanho, representatividade, importância para a empresa ou a capacitação logística para melhor atendê-lo.

Os resultados não permitiram, porém, estabelecer uma relação clara entre os segmentos de clientes por necessidades/benefícios e variáveis facilmente utilizáveis pelos fornecedores, tais como a localização geográfica, o tipo de produto comprado, a forma de comprar e o tamanho, representado pelo número de checkouts. Para a solução de segmentação com dois grupos, apenas a variável localização logrou mostrar alguma distinção entre os grupos de complacentes e exigentes e, ainda assim, apenas respectivamente para as cidades de Rio de Janeiro e São Paulo. Embora tenha sido uma surpresa encontrar o Rio de Janeiro entre as cidades de menor exigência, é possível que tal resultado tenha relação com o baixo nível de insatisfação dos varejistas cariocas quanto ao serviço de distribuição física evidenciado no estudo de Lavalle (2003), no qual se observou um índice de insatisfação de apenas $9 \%$ no Rio de Janeiro, comparado a $46 \%$ na cidade de São Paulo. 
Já na solução de três segmentos, além da concentração de varejistas do Rio de Janeiro entre os complacentes e de São Paulo entre os exigentes, foi possível apenas diferenciar os bem informados dos demais por variáveis de fácil acesso. Como anteriormente observado, estes se caracterizam pela maior presença de varejistas de Belo Horizonte e Recife, compradores de produtos de higiene e limpeza e de papel, com 5 a 20 checkouts. No entanto, sendo este grupo numericamente pouco representativo, dificilmente se justificaria investir para servilo de maneira diferenciada.

Ainda que São Paulo tenha aparecido como mercado um pouco mais exigente, a distinção regional, utilizada por muitas empresas como base para a segmentação e estabelecimento de políticas de serviço, não se mostrou claramente sustentável. Assim, não foi possível encontrar variáveis de fácil acesso que representassem, de maneira satisfatória, os grupos encontrados por uma segmentação por benefícios. Ainda que a proposta de Sharma e Lambert (1994) seja muito interessante, os resultados encontrados corroboram trabalhos anteriores, desenvolvidos em outros contextos, que também não conseguiram encontrar uma relação satisfatória entre as variáveis tradicionais e a segmentação por benefícios (Moriarty \& Reibstein, 1986; Rao \& Wang, 1995).

O grande desafio continua sendo a adequação da oferta de serviços logísticos às necessidades de cada segmento de clientes. A dificuldade de identificação nítida de grupos regionais, evidenciada neste estudo, implica que o custo para um fornecedor atender com um mesmo nível de serviço a um grupo com expectativas semelhantes, mas muito disperso geograficamente, pode ser muito alto e, às vezes, impraticável.

Por fim, é importante ressaltar que cabe a cada empresa avaliar a estratégia de atuar em um ou mais segmentos identificados, verificando se os tamanhos dos grupos são estrategicamente adequados para a empresa, estabelecendo em quantos segmentos deve atuar e verificando se a posição obtida nos segmentos escolhidos é estrategicamente defensável. Este cuidado é requisito fundamental na definição do posicionamento, primeira competência a ser desenvolvida pelas empresas que desejam ter uma logística de classe mundial.

Futuros estudos poderão investigar este fenômeno em perspectiva longitudinal, com base em levantamentos repetidos junto à mesma população, de forma a testar a estabilidade dos grupos gerados, assim como de suas características. Recomenda-se, igualmente, a replicação do estudo em outros contextos, de forma a propiciar novas evidências quanto à aplicabilidade mais ampla dos conhecimentos aqui gerados.

Artigo recebido em 05.11.2004. Aprovado em 23.03.2005. 


\section{ReferênCias Bibliográficas}

Bowersox, D. J., \&

Closs, D. J. (1996).

Logistical management: the integrated supply chain process. New York, NY: McGraw-Hill.

Bowersox, D. J.,

Closs, D. J.,

Goldsby, T. J., \&

Stank, T. P. (1998).

World class logistics: 1998 North American research. Proceedings of the Annual Conference of the Council of Logistics Management, Oak Brook, Il., USA, 1.

Bowersox, D. J., \&

Cooper, M. B. (1992).

Strategic marketing channel management. New York, NY: McGrawHill.

Christopher, M. (1983).

Creating effective policies for customer service. International Journal of Physical Distribution and Materials Management, 13(2), 3-24.

Christopher, M. (1992).

Logistics and supply chain management. London, U.K: Pitman.

Collins, A.,

Henchion, M., \&

O’Reilly, P. (2001).

Logistics customer service: performance of Irish food exporters. International Journal of Retail and Distribution Management, 29(1), 615.
Council of Logistics Management (1995). World class logistics: the challenge of managing continuous change. Oak Brook, II:Author.

Díaz-Martin, A. M., Iglesias, V.,

Vasquez, R., \&

Ruiz,A. V. (2000).

The use of quality expectations to segment a service market. Journal of Services Marketing, 14(2-3), 132-146.

Ellram, L. M.,

La Londe, B., \&

Weber, M. M. (1999).

Retail logistics. International Journal of Physical Distribution and Logistics Management, 29(7-8), 477494.

Emerson, C. J., \& Grimm, C.M. (1996).

Logistics and marketing components of customer service: an empirical test of the Mentzer, Gomez and Krafkel model. International Journal of Physical Distribution and Logistics Management, 26(8), 29-42.

Hair Jr., J. F.,

Anderson, R. E.,

Tatham, R. L., \&

Black, W. C. (1998).

Multivariate data analysis. Upper Saddle River: Prentice Hall.

Heskett, J. L. (1994).

Controlling customer logistics service. International Journal of Physical Distribution and Logistics Management, 24(4), 4-10. 
La Londe, B. J.,

Cooper, M. C., \&

Noordewier, T. G. (1988).

Customer service: a management perspective. Oak Brook: Council of Logistics Management.

Lambert, D. M. (1992).

Developing a customer-focused logistics strategy. International Journal of Physical Distribution and Logistics Management, 22(6), 12-17.

Lambert, D. M., \&

Harrington, T. C. (1989).

Establishing customer service strategies within the marketing mix: more empirical evidence. Journal of Business Logistics, 24(10), 44-60.

Lambert, D. M.,

Stock, J. R., \&

Ellram, L. M. (1998).

Fundamentals of logistics management. Homewood: McGrawHill/Irwin.

Lavalle, C. (2003).

Pesquisa benchmark - serviço ao cliente (1994; 1995; 1998; 1999; 2000; 2001; 2002). Centro de Estudos em Logística. Recuperado em fevereiro, 2004, de http:// www.cel.coppead.ufrj.br/new/ pesquisa_benchmark.pdf

Mangold, W. G., \&

Faulds, D. J. (1993).

Service quality in a retail channel system. Journal of Service Management, 7(4), 4-10.
Moriarty, R. T., \&

Reibstein, D. J. (1986).

Benefit segmentation in industrial marketing. Journal of Business Research, 14(6), 463-486.

Murphy, P. R., \&

Daley, J. M. (1994).

A framework for applying logistical segmentation. International Journal of Physical Distribution and Logistics Management, 24(10), 13-19.

Rao, C. P., \&

Wang, Z. (1995).

Evaluating alternative segmentation strategies in standard industrial markets. European Journal of Marketing, 29(2), 58-75.

Saab, W. G. L., \&

Gimenez, L. C. P. G. (2000).

Aspectos atuais do varejo de alimentos no mundo e no Brasil. BNDES Setorial, 11, 101-122.

Shapiro, B. P., \&

Bonoma, T. V. (1984).

How to segment industrial markets. Harvard Business Review, 62(3), 104110.

Sharma, A., \&

Lambert, D. M. (1994).

Segmentation of markets based on customer service. International Journal of Physical Distribution and Logistics Management, 24(4), 50-58.

Stock, J. R., \&

Lambert, D. M. (1992).

Becoming a 'world class' company with logistics service quality. International Journal of Logistics Management, 3(1), 73-80 
Tucker, F. G. (1994).

Creative customer service management. International Journal of Physical Distribution \& Logistics Management, 24(4), 32-40.
Veeken, D. J. M. van der, \& Rutten, W. G. M. (1998).

Logistics service management: opportunities for differentiation. International Journal of Logistics Management, 9(2), 91-98.75 
